\title{
Survival and differentiation defects contribute to neutropenia in glucose-6-phosphatase- $\beta$ (G6PC3) deficiency in a model of mouse neutrophil granulocyte differentiation
}

\author{
S Gautam ${ }^{1,2,3}$, S Kirschnek ${ }^{1}$, IE Gentle ${ }^{1}$, C Kopiniok ${ }^{1}$, P Henneke ${ }^{4}$, H Häcker ${ }^{5}$, L Malleret ${ }^{6}$, A Belaaouaj ${ }^{6}$ and G Häcker ${ }^{*, 1}$
}

Differentiation of neutrophil granulocytes (neutrophils) occurs through several steps in the bone marrow and requires a coordinate regulation of factors determining survival and lineage-specific development. A number of genes are known whose deficiency disrupts neutrophil generation in humans and in mice. One of the proteins encoded by these genes, glucose6-phosphatase- $\beta$ (G6PC3), is involved in glucose metabolism. G6PC3 deficiency causes neutropenia in humans and in mice, linked to enhanced apoptosis and ER stress. We used a model of conditional Hoxb8 expression to test molecular and functional differentiation as well as survival defects in neutrophils from $\mathrm{G}_{6 \mathrm{PC}} 3^{-1-}$ mice. Progenitor lines were established and differentiated into neutrophils when Hoxb8 was turned off. G6PC3 ${ }^{-I-}$ progenitor cells underwent substantial apoptosis when differentiation was started. Transgenic expression of $\mathrm{Bcl}-\mathrm{X}_{\mathrm{L}}$ rescued survival; however, $\mathrm{Bcl}-\mathrm{X}_{\mathrm{L}}$-protected differentiated cells showed reduced proliferation, immaturity and functional deficiency such as altered MAP kinase signaling and reduced cytokine secretion. Impaired glucose utilization was found and was associated with ER stress and apoptosis, associated with the upregulation of Bim and Bax; downregulation of Bim protected against apoptosis during differentiation. ER-stress further caused a profound loss of expression and secretion of the main neutrophil product neutrophil elastase during differentiation. Transplantation of wild-type Hoxb8-progenitor cells into irradiated mice allowed differentiation into neutrophils in the bone marrow in vivo. Transplantation of $\mathrm{G6PC} 3^{-1-}$ cells yielded few mature neutrophils in bone marrow and peripheral blood. Transgenic Bcl- $\mathrm{X}_{\mathrm{L}}$ permitted differentiation of $\mathrm{G6PC} 3^{-I-}$ cells in vivo. However, functional deficiencies and differentiation abnormalities remained. Differentiation of macrophages from Hoxb8-dependent progenitors was only slightly disturbed. A combination of defects in differentiation and survival thus underlies neutropenia in $\mathrm{G} 6 \mathrm{PC} 3^{-1-}$ deficiency, both originating from a reduced ability to utilize glucose. Hoxb8-dependent cells are a model to study differentiation and survival of the neutrophil lineage.

Cell Death and Differentiation (2013) 20, 1068-1079; doi:10.1038/cdd.2013.39; published online 17 May 2013

Neutrophils differentiate in the bone marrow from promyelocytes in a series of steps identifiable by changes in morphology and sometimes protein expression. Key regulators like the transcription factor CCAAT/enhancer-binding protein $\alpha(\mathrm{C} / \mathrm{EBP} \alpha)$ drive programs through numerous target genes, causing the typical morphology and expression of a pattern of differentiation markers. Numerous aspects of the process, where differentiation is coordinated with survival of the differentiating cells, are not well understood.

A number of clinical situations are known where patients present with neutropenia, defined as a neutrophil count of less than 1500 per $\mu \mathrm{l}$ in peripheral blood. In severe congenital neutropenia (SCN), patients typically present with invasive bacterial infections. ${ }^{1}$ The first form of SCN was clinically recognized in $1950^{2}$ but the genetic basis of most cases was only identified in recent years. SCN can be caused by mutations in known genes coding for individual proteins, for instance HCLS1-associated protein X-1 (Hax1), growth factor independent 1, neutrophil elastase (NE; ELA2) and G6PC3. ${ }^{3}$ Bone marrow examination typically shows the presence of early myeloid progenitors up to the promyelocyte stage with a paucity of mature granulocytes. ${ }^{1,3}$

The underlying molecular mechanisms are incompletely understood. The affected genes do not operate obviously in a

\footnotetext{
${ }^{1}$ Institute for Medical Microbiology and Hygiene, University Medical Center, Freiburg, Germany; ${ }^{2}$ Spemann Graduate School of Biology and Medicine, University of Freiburg, Freiburg, Germany; ${ }^{3}$ Faculty of Biology, University of Freiburg, Freiburg, Germany; ${ }^{4}$ Center for Pediatrics and Center of Chronic Immunodeficiency, University Medical Centre Freiburg, Freiburg, Germany; ${ }^{5}$ Department of Infectious Diseases, St. Jude Children's Research Hospital, Memphis, USA and ${ }^{6}$ Inserm Avenir and EA 4303 'Inflammation and Immunity of the Respiratory Epithelium', CHU de Reims, Maison Blanche, Reims, France

${ }^{*}$ Corresponding author: G Häcker, Institute of Medical Microbiology and Hygiene, University Medical Center, Hermann-Herder-Street 11, Freiburg D-79104, Germany. Tel: + 49761203 6531; Fax: + 49761203 6551; E-mail: georg.haecker@uniklinik-freiburg.de

Keywords: neutropenia; apoptosis; differentiation

Abbreviations: 2DG, 2-deoxy glucose; BH3 domain, Bcl-2 homology domain 3; G-CSF, granulocyte colony-stimulating factor; IL-6, interleukin 6; LPS, lipopolysaccharide; Mcl-1, induced myeloid leukemia cell differentiation protein 1; NE, neutrophil elastase; SCF, stem cell factor; SCN, severe congenital neutropenia; TNF, tumor necrosis factor; wt, wild type; GRP-78, glucose-regulated protein 78 kDa; Hax1, HCLS1 associated protein X-1; C/EBP, CCAAT/enhancer-binding protein; CXCR, chemokine (C-X-C motif) receptor; GFP, green fluorescent protein

Received 06.11.12; revised 03.4.13; accepted 05.4.13; Edited by G Rabinovich; published online 17.5.13
} 
common pathway. ${ }^{1}$ Hax1, for instance, may have an anti-apoptotic role ${ }^{4}$ and have a role in cell motility. ${ }^{5}$ Mutations in ELA2 cause cyclic neutropenia or SCN and have been proposed to do this by the generation of a misfolded protein, which induces ER stress and apoptotic loss of the cells. ${ }^{6,7}$

G6PC3 (glucose-6-phosphatase (G6Pase)- $\beta$ ) is one of two enzymes that hydrolyze glucose-6-phosphate to glucose in the ER, which is important for energy storage. Although G6Pase- $\alpha$ is expressed in the organs of gluconeogenesis such as kidney, liver and the intestine, ${ }^{8}$ G6PC3/G6Pase- $\beta$ is expressed ubiquitously. ${ }^{9}$ Mutations in G6PC3 in humans cause $\mathrm{SCN}^{10-12}$ and additional problems in various organ systems. ${ }^{1,13}$ Peripheral blood neutrophils isolated from patients with G6PC3 deficiency showed increased apoptosis in vitro and fibroblasts derived from these patients underwent increased apoptosis upon treatment with dithiothreitol. ${ }^{10}$

Mice genetically deficient in G6PC3 display neutropenia, and neutrophils isolated from these mice show a defect in oxidative burst, calcium flux and chemotaxis toward fMLP, KC and MIP-2. ${ }^{14}$ Peritoneal neutrophils and bone marrow cells from $\mathrm{G}_{6 \mathrm{PC}}{ }^{-1-}$ mice further show enhanced levels of the marker of ER stress, GRP78, perhaps linked to higher levels of spontaneous apoptosis in isolated peritoneal neutrophils. ${ }^{14,15}$ Metabolically, the defect has been linked to the lack of ER-cytosol shuttling of glucose. ${ }^{15}$

Although these studies are valuable, they are limited by the lack of sufficient suitable cellular material and the option of genetic modification. Little material from human patients is available, and cells isolated from mice cannot be easily genetically modified to assess changes associated with alterations in specific pathways. It is therefore almost impossible to separate survival- from maturation-deficiencies. In humans, the lack of more mature cells may be due to increased apoptosis or a block in differentiation. In mice, apparently incomplete maturation as suggested by nuclear morphology in isolated G6PC $3^{-1-}$ neustrophils ${ }^{16}$ and a higher expression of chemokine (C-X-C motif) receptor 4 (CXCR4) ${ }^{17}$ may be linked to either apoptosis of the more mature cells or an intrinsic maturation defect. As enhanced apoptosis would interfere with cellular functions, it is very difficult to work out the functional consequences of the loss of G6PC3.

We aimed at overcoming these limitations and at understanding the contribution of cell death versus differentiation alterations to the effects of G6PC3 deficiency. We therefore made use of the possibility to establish murine neutrophil progenitor cells by conditional expression of active Hoxb8. Hoxb8 is fused to the estrogen receptor ligand-binding domain (ER-Hoxb8). In the presence of estrogen, ER-Hoxb8 drives the expansion of neutrophil progenitor cells. When Hoxb8 is turned off by estrogen withdrawal, the cells differentiate into cells that are almost indistinguishable from primary mature neutrophils. ${ }^{18,19}$ Neutrophil Hoxb8 progenitors lie slightly before the promyelocyte stage (by morphology and CD11b negativity) and turning off Hoxb8 induces maturation (in the presence of stem cell factor (SCF)/c-kit-signaling) in vitro. Differentiation of primary neutrophils is very difficult to examine in the bone marrow, primarily because it is challenging to isolate larger numbers of neutrophil differentiation stages. Maturation can, however, be studied in the Hoxb8 model in vitro.
We here use this model to analyze the consequence of the loss of G6PC3 on survival and for differentiation and functional defects of neutrophils. By transplanting progenitor cells into irradiated mice, it was possible to distinguish survival and functional defects of $\mathrm{GPPC}^{-/-}$cells of the granulocyte lineage in a wild-type (wt) environment.

\section{Results}

The Hoxb8 system permits the easy production, genetic manipulation and analysis of cells that are very similar to mature neutrophils. It also allows for the analysis of neutrophil differentiation from progenitor cells. By morphology and the expression of surface markers, these progenitor cells lie slightly before promyelocytes ${ }^{18,19}$ (and below). During differentiation of Hoxb8 progenitor cells, expression patterns of transcription factors (e.g., SFFV proviral integration 1, $\left.\mathrm{C} / \mathrm{EBP} \alpha, \mathrm{C} / \mathrm{EBP} \beta, \mathrm{C} / \mathrm{EBP}_{\varepsilon}\right)$ and surface markers (CD11b, Gr-1, CXCR2, CXCR4, c-kit) follow a pattern that is very similar to the one found in studies of human neutrophil differentiation. ${ }^{20}$

Bone marrow cells from wt or $\mathrm{G} 6 \mathrm{PC} 3^{-1-}$ mice $^{21}$ were transduced with an ER-Hoxb8 retrovirus and cell lines were established. Cell lines from wt and $\mathrm{G} 6 \mathrm{PC}^{-1-}$ bone marrow could both be easily established although a higher rate of spontaneous death was observed in $\mathrm{GPPC}^{-1-}$ cells in continuous culture (Figure 1a). The morphology of these progenitor cells was also similar but $\mathrm{G}_{6 \mathrm{PC}}{ }^{-1-}$ cells were slightly smaller (Figures $1 \mathrm{~b}$ and $\mathrm{c}$ ). Estrogen withdrawal deactivates ER-Hoxb8 and starts differentiation, with wt cells attaining mature neutrophil morphology in about 4 days of culture in SCF (Figure 1b). G6PC3 ${ }^{-1-}$ cells also commenced differentiation. No gross morphological differences were observed by day 2. On day 4, fewer cells were left in $\mathrm{G} 6 \mathrm{PC} 3^{-1-}$ cultures, and these cells displayed an immature morphology (Figure $1 \mathrm{~b}$ ) and now were slightly bigger than mature wt cells, probably indicative of a maturation defect, as maturation is paralleled by size reduction (Figure 1c).

Differentiated $\mathrm{G}_{6 \mathrm{PC}}{ }^{-1-}$ cells were negative for surface expression of Gr-1 but positive for CD11b, and the downregulation of $c$-kit was less complete (Figure 1d). The upregulation of CXCR2 was reduced, and the downregulation of CXCR4 was not seen in G6PC3 ${ }^{-l-}$ cells (Figure 1d).

Expression of G6PC3-mRNA was highest in progenitor cells and decreased during differentiation (Figure 2a). G3PC $^{-1-}$ progenitor cells showed reduced glucose uptake as evidenced by glucose levels in the culture medium (Figure $2 b$, left panel), indicating that the enzyme is active in progenitor cells. Experiments measuring incorporation of radiolabeled glucose demonstrated a reduced uptake on a per-cell basis (Figure $2 b$, right panel).

Upon initiation of differentiation cell death in $\mathrm{G}_{\mathrm{PPC}}{ }^{-1}$ - cell lines increased to some extent, and more dead cells were observed in differentiating cells compared with progenitor cells (Figure 2c). Almost all cell death seemed to occur either at the progenitor stage or on the first day of differentiation (Figures 1a and 2c). Granulocyte colony-stimulating factor (G-CSF) addition had no protective effect (Figures $2 f$ and g). Stimulation with pro-inflammatory mediators prolongs life 

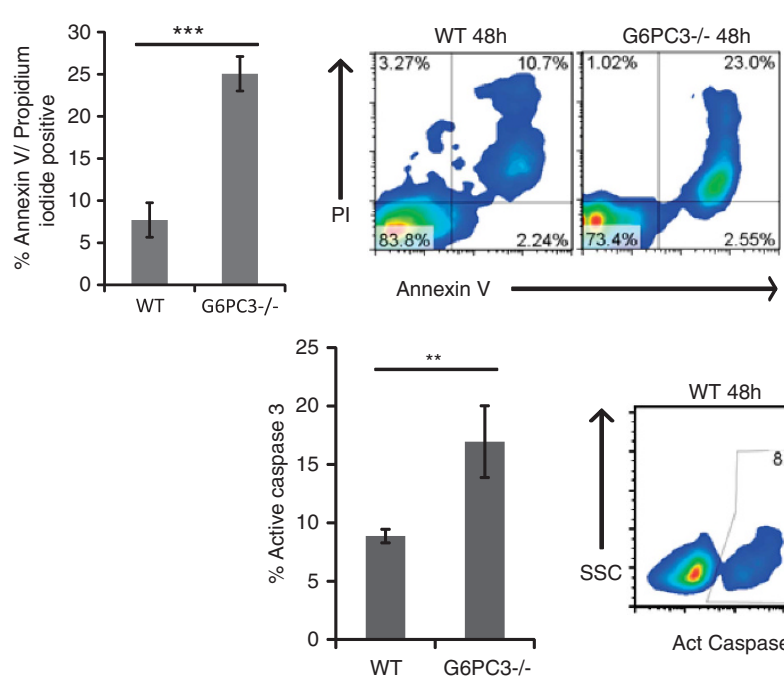

b
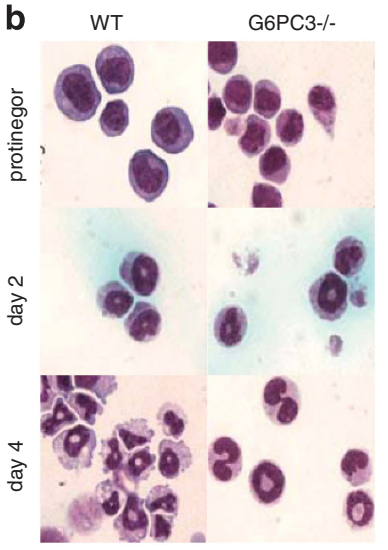

WT $48 \mathrm{~h}$
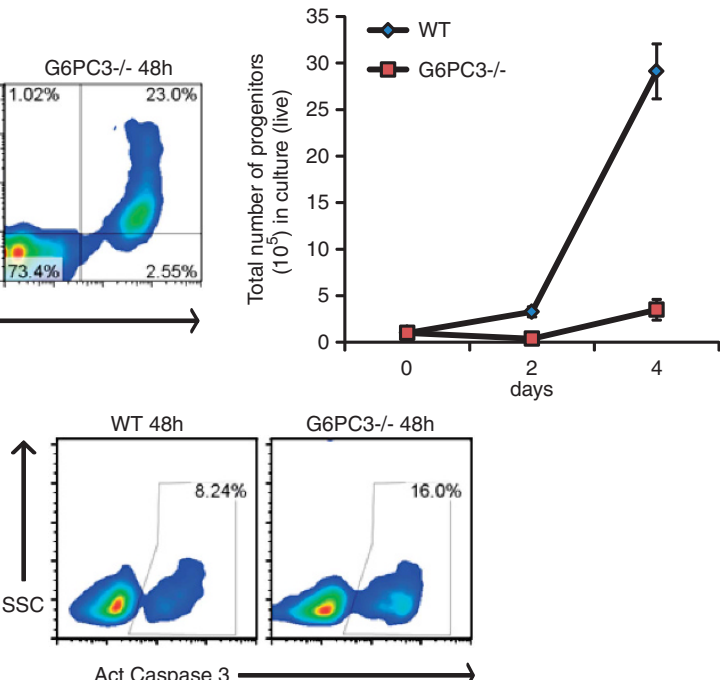

Act Caspase $3 \longrightarrow$

C progenitor

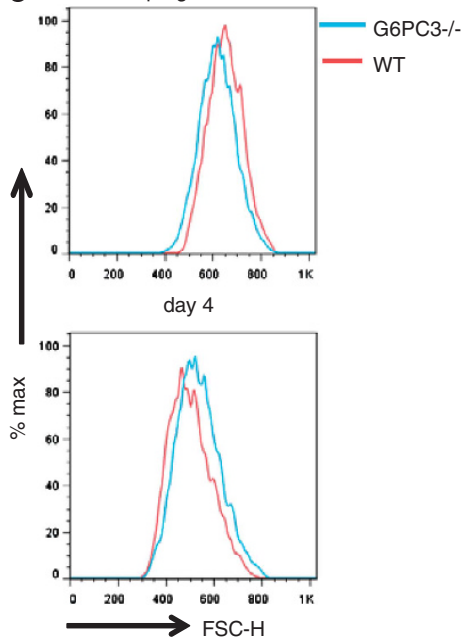

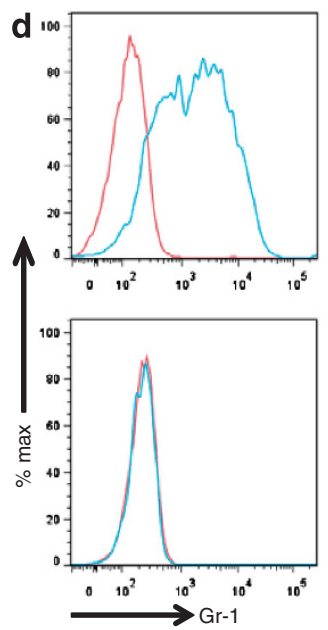
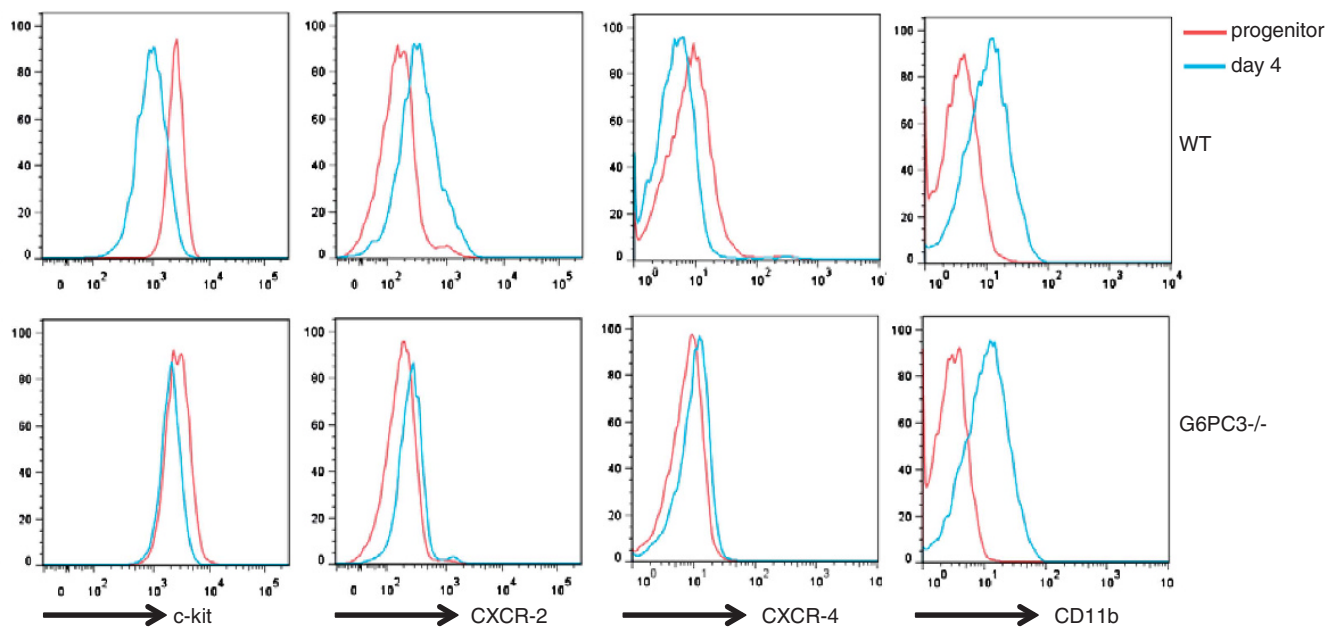

Figure 1 Accelerated spontaneous apoptosis and maturation defects in G6PC3-deficient progenitors. (a) Top, left and middle panel, annexin V/propidium iodide staining of wild-type and $\mathrm{G} 6 \mathrm{PC} 3^{-1}$ progenitors cultured in vitro for $48 \mathrm{~h}$ (the dot plot shows one of the experiments included in the left panel). Right panel, cell numbers as obtained by counting the cells at the days indicated upon seeding the same number of cells as in the left panel. Bottom panels, active caspase-3 staining of wild-type and G6PC ${ }^{-1-}$ progenitors cultured in vitro for $48 \mathrm{~h}$. Values are means of three individual experiments, error bars represent standard deviation. Statistical significance was calculated using t-test; ${ }^{* * *} P<0.001,{ }^{* *} P<0.01$. (b) Giemsa stain appearance of cytospin sample of wild-type and G6PC3-deficient cells at progenitor stage or on day 2 or 4 of differentiation, $\times 630$ magnification. (c) Forward scatter profiles of progenitors or day 4 differentiated wild-type and G6PC-deficient neutrophils. (d) Flow cytometry analysis of expression of Gr-1, c-kit, CXCR-2 and CXCR-4, CD11b by wild-type and G6PC3-deficient progenitors and differentiated neutrophils 
a

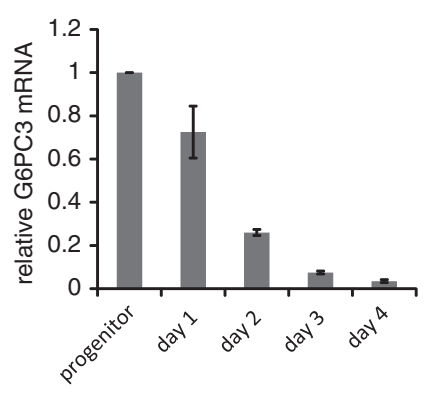

b

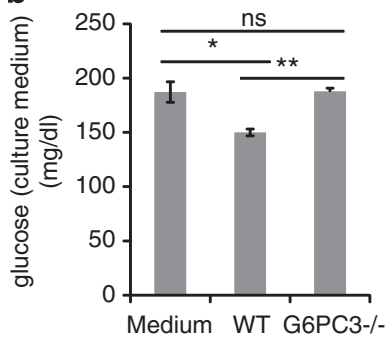

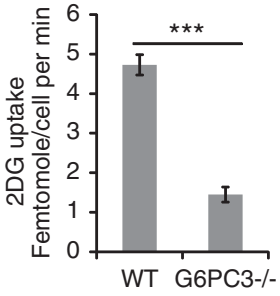

C

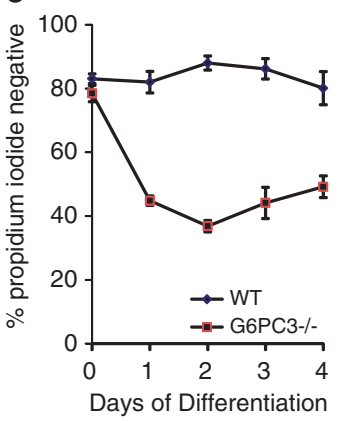

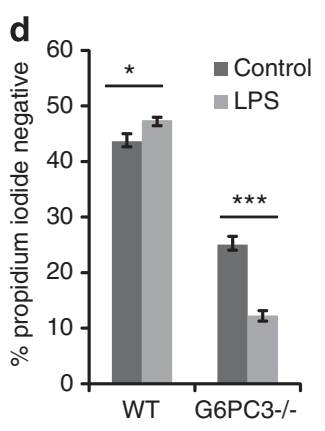

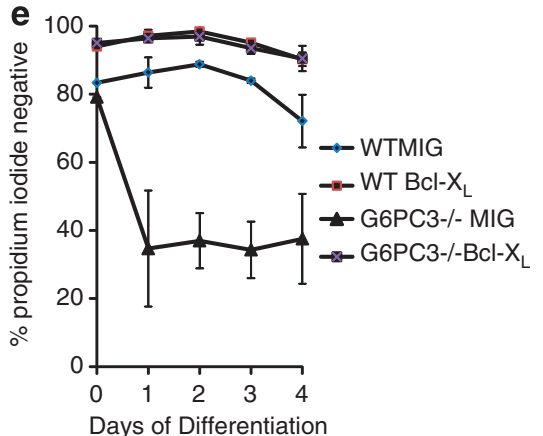

Days of Differentiation
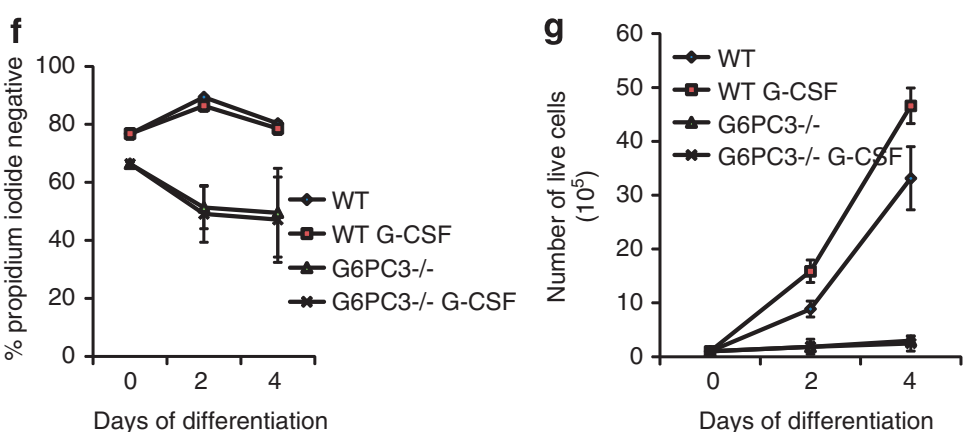

Figure 2 Reduced glucose uptake and accelerated apoptosis of G6PC3 $3^{-/-}$neutrophils. (a) qPCR measurement of G6PC3 expression in wild-type neutrophils on different days of differentiation. Data give means and error bars represent S.D. from three independent experiments. (b) Glucose uptake and utilization by progenitor cells. Left panel, glucose concentration in medium obtained from a 48 -h culture of $10^{6}$ wild-type or G6PC3 ${ }^{-1-}$ progenitors. Right panel, 2-deoxy glucose (2DG) uptake by a cell per minute as measured by incorporation of radiolabeled 2DG. Data give means and error bars represent S.D. from three independent experiments. (c) Cell death analysis (propidium iodide staining) of wild-type and G6PC3 ${ }^{-1}$ neutrophils on different days of differentiation. Data give means/S.D. from three independent experiments. (d) Cell death analysis (propidium iodide staining) of differentiated wild-type and $\mathrm{G}_{\mathrm{PPC}}{ }^{-1-}$ neutrophils after $10 \mathrm{~h}$ of LPS stimulation. Data give means/S.D. from three independent experiments. (e) Cell death analysis (propidium iodide staining) of wild-type and G6PC-deficient differentiating progenitors transduced with retrovirus driving expression of $\mathrm{Bcl}-\mathrm{X}_{\mathrm{L}}$ or carrying the empty retroviral vector (pMIG) Data give means/S.D. from three independent experiments. (f) Cell death analysis of wt and G6PC3 - / - progenitors during differentiation in the presence or absence of rG-CSF $(20 \mathrm{ng} / \mathrm{ml})$ in the culture medium. (g) Number of wt and G6PC3 ${ }^{-1-}$ neutrophils in culture on day 2 and day 4 of differentiation in the presence or absence of rG-CSF $(20 \mathrm{ng} / \mathrm{ml})$ in the culture medium. Statistical significance was calculated using $t$-test. ${ }^{*} P<0.05,{ }^{* \star} P<0.01,{ }^{* \star \star} P<0.001$. ns, non-significant $(P>0.05)$

span of neutrophils by reducing apoptosis. ${ }^{22}$ In $\mathrm{G} 6 \mathrm{PC} 3^{-1-}$ cells, lipopolysaccharide (LPS) failed to inhibit but instead increased cell death (Figure 2d).

These results confirm the reported high sensitivity to cell death of $\mathrm{G} 6 \mathrm{PC} 3^{-1-}$ neutrophils and extend this observation to neutrophil progenitors, which may contribute to neutropenia in patients. They further suggest that surviving $\mathrm{G} 6 \mathrm{PC}^{-1-}$ neutrophils may have maturation defects. To separate cell death from maturation defects, we overexpressed the antiapoptotic protein $\mathrm{Bcl}-\mathrm{X}_{\mathrm{L}}$ by retroviral transduction of progenitor cells (Supplementary Figure 1 ). Bcl- $X_{\mathrm{L}}$ completely rescued differentiating cells from cell death $\left(\mathrm{G} 6 \mathrm{PC}^{-l-}-\mathrm{Bcl}-\mathrm{X}_{\mathrm{L}}\right.$ cells; Figure 2e).
G-CSF is used therapeutically in SCN, and G-CSF corrected neutropenia in G6PC3-deficient cells. ${ }^{16}$ On mature neutrophils, G-CSF has some anti-apoptotic effect, which is also seen in G6PC3-deficient cells. ${ }^{16}$ However, G-CSF did not protect against apoptosis during differentiation of G6PC3deficient progenitor cells (Figure 2f) Total cell numbers during differentiation were increased in wt cells treated with G-CSF, but no increase was seen in G6PC3-deficient cells (Figure 2g), suggesting that there is no effect of G-CSF on survival or proliferation in differentiating G6PC3-deficient cells.

Although $\mathrm{BCl}-\mathrm{X}_{\mathrm{L}}$ overexpression protected $\mathrm{G} 6 \mathrm{PC} 3^{-1-}$ cells from apoptosis, $\mathrm{G}_{6 \mathrm{PC}}{ }^{-1-}-\mathrm{Bcl}-\mathrm{X}_{\mathrm{L}}$ cells still showed reduced 
proliferation during differentiation (Figure $3 a$ ). $\mathrm{Bcl}-\mathrm{X}_{\mathrm{L}}$ appeared to reduce or delay maturation: $\mathrm{Bcl}-\mathrm{X}_{\mathrm{L}}$ overexpressing, day 4 differentiated wt cells had a slightly less mature appearance than wt cells without $\mathrm{Bcl}-\mathrm{X}_{\mathrm{L}}$ (Figures $3 \mathrm{~b}$ and $1 \mathrm{~b}$ ). $\mathrm{G} \mathrm{PC} 3^{-1-}-\mathrm{Bcl}-\mathrm{X}_{\mathrm{L}}$ cells retained a more immature morphology than $\mathrm{Bcl}-\mathrm{X}_{\mathrm{L}}$-expressing wt cells (Figure $3 \mathrm{~b}$ ). However, $\mathrm{G} 6 \mathrm{PC}^{-1-}-\mathrm{Bcl}-\mathrm{X}_{\mathrm{L}}$ cells showed a pattern of surface markers very similar to the one seen in wt cells (Figure $3 \mathrm{c}$ ). Inhibition of apoptosis could thus improve maturation of the cells but differentiation was still incomplete.

Inhibition of apoptosis permitted functional analysis of $\mathrm{G} 6 \mathrm{PC}^{-1-}-\mathrm{Bcl}-\mathrm{X}_{\mathrm{L}}$ cells. As shown previously for primary $\mathrm{G} \mathrm{PC} 3^{-1-}$ neutrophils, ${ }^{14}$ differentiated $\mathrm{G}^{-1} \mathrm{PC} 3^{-/-}-\mathrm{Bcl}-\mathrm{X}_{\mathrm{L}}$ cells were unable to produce reactive oxygen species (Figure 4a). The cells also produced significantly less tumor necrosis factor (TNF) and less interleukin 6 (IL-6) upon stimulation (Figures $4 \mathrm{~b}$ and $\mathrm{c}$ ). Analysis of MAPK-signaling during stimulation with LPS or phorbol ester in mature $\mathrm{G}_{6 \mathrm{PC}} 3^{-1-}-\mathrm{BCl}-\mathrm{X}_{\mathrm{L}}$ cells showed a relatively normal pattern in $\mathrm{G} 6 \mathrm{PC} 3-\mathrm{Bcl}-\mathrm{X}_{\mathrm{L}}$ cells with the exception that JNK-phosphorylation was reduced (Figure $4 d$ ). Enhanced apoptosis is thus not the only defect, as cells kept alive by $\mathrm{Bcl}-\mathrm{X}_{\mathrm{L}}$ have relatively subtle maturation defects but severe functional defects.
$\mathrm{Bcl}-\mathrm{X}_{\mathrm{L}}$ expression permits initiation of upstream apoptosis events but blocks at the mitochondrial level. ${ }^{23}$ The use of $\mathrm{G} \mathrm{PC} 3^{-1-}-\mathrm{Bcl}-\mathrm{X}_{\mathrm{L}}$ cells therefore allows the analysis of the initial steps of apoptosis but avoids confounding effects of ongoing cell death.

Mitochondrial apoptosis is regulated by the $\mathrm{Bcl}-2$ family of proteins. The anti-apoptotic proteins, Bcl-2 and Bcl-w, and the pro-apoptotic proteins, Bak and Bid, were expressed at similar levels at all stages of differentiation in wt-Bcl- $\mathrm{X}_{\mathrm{L}}$ and G6PC3$\mathrm{Bcl}-\mathrm{X}_{\mathrm{L}}$ cells (Figures $5 \mathrm{a}$ and $\mathrm{b}$; the pattern of expression of $\mathrm{Bcl}-2$-family members in these $\mathrm{Bcl}-\mathrm{X}_{\mathrm{L}}$-overexpressing cells was similar to the one reported previously for non-transgenic Hoxb8 cells ${ }^{19}$ ). There was a slight reduction in induced myeloid leukemia cell differentiation protein 1 (Mcl-1) levels and an upregulation of the pro-apoptotic protein Bax during differentiation of G6PC3-Bcl-X $X_{L}$ cells (Figures 5 and b). The most striking difference, however, was a strong upregulation of the pro-apoptotic Bcl-2 homology domain 3 (BH3)-only protein Bim in G6PC3-Bcl- $\mathrm{X}_{\mathrm{L}}$ cells, both in progenitors and during differentiation (Figure $5 \mathrm{c}$; upregulation of Bim was also observed in wt-Bcl- $X_{L}$ cells during differentiation; we have found Bim upregulation in wt Hoxb8 cells during differentiation previously ${ }^{19}$ ).

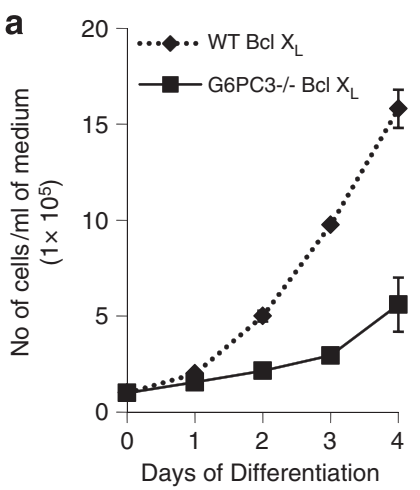

b
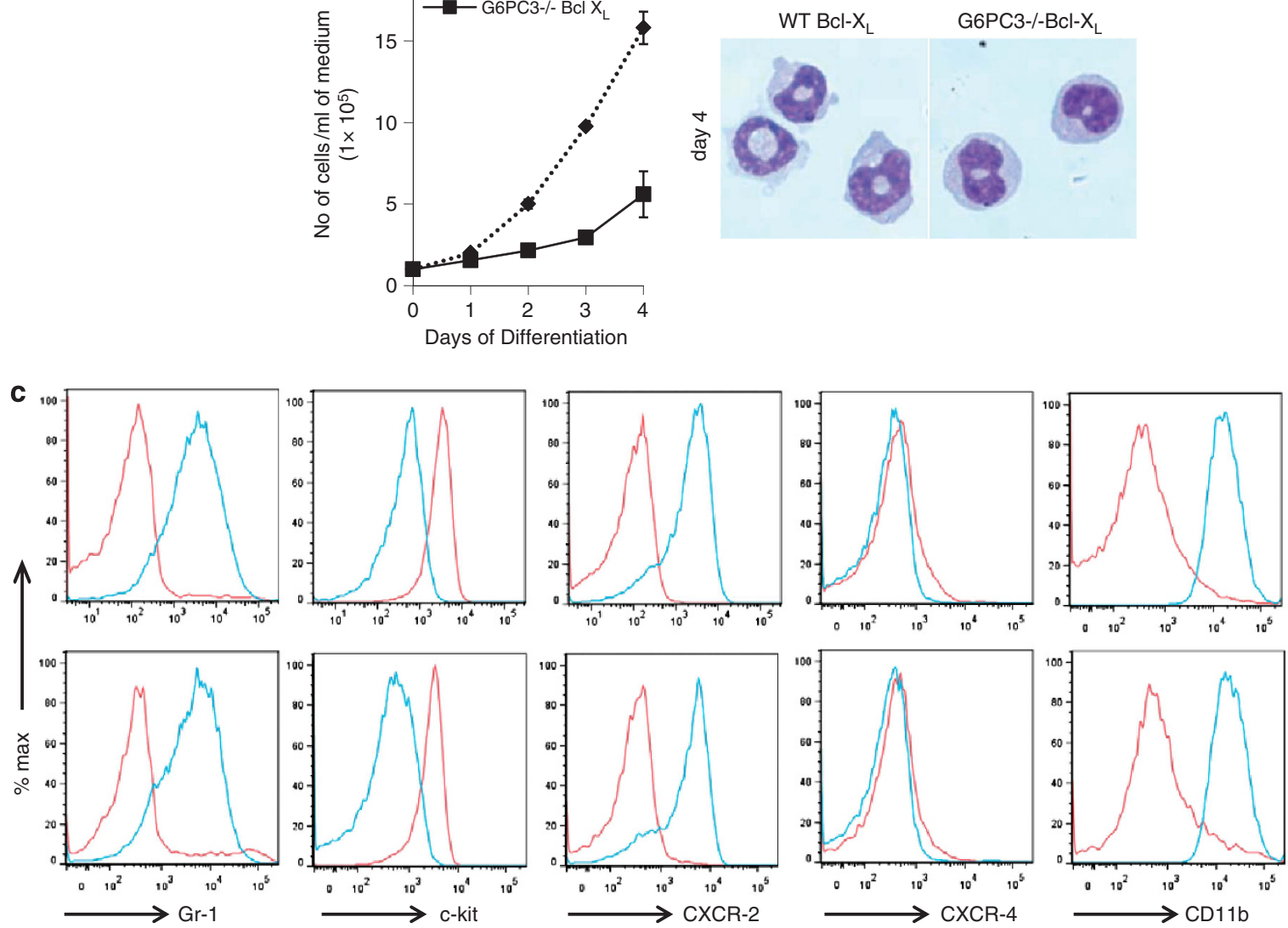

progenitor

day 4

WT BCl-X
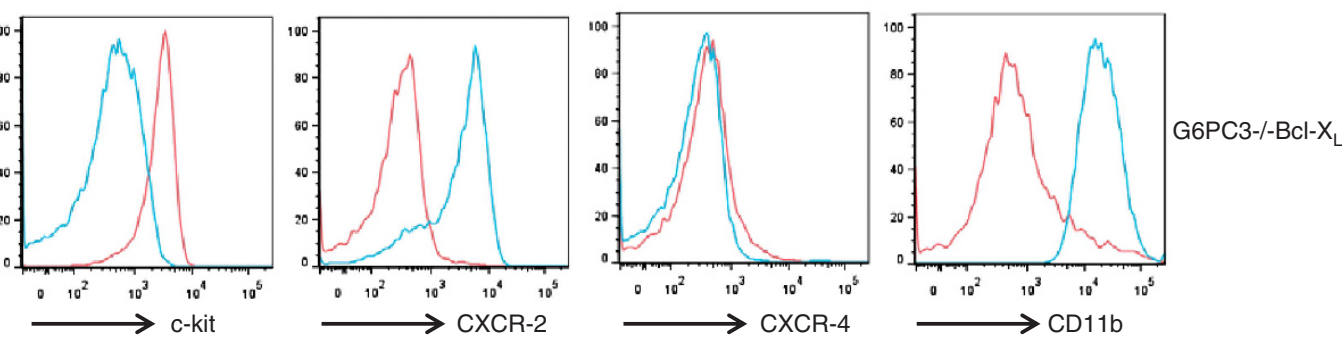

Figure 3 Proliferation and differentiation of G6PC-deficient neutrophils expressing $\mathrm{Bcl}-\mathrm{X}_{\mathrm{L}}$. (a) Number of wild-type and $\mathrm{G} 6 \mathrm{PC} 3^{-1-}$ cells on different days of differentiation. (b) Giemsa stain appearance of day 4 differentiated wt-Bcl- $X_{L}$ and G6PC3-Bcl-X cells (magnification $\times 630 \times$ ). (c) Surface marker expression (Gr-1, CD11b, c-kit, CXCR-2, CXCR-4, CD11b) on wt-Bcl- $X_{\mathrm{L}}$ and G6PC3-Bcl- $\mathrm{X}_{\mathrm{L}}$ progenitors and day 4 differentiated neutrophils. Data are means and error bars show S.D. from four independent experiments. (b and $\mathbf{c})$ Data are representative of similar results in three independent experiments 

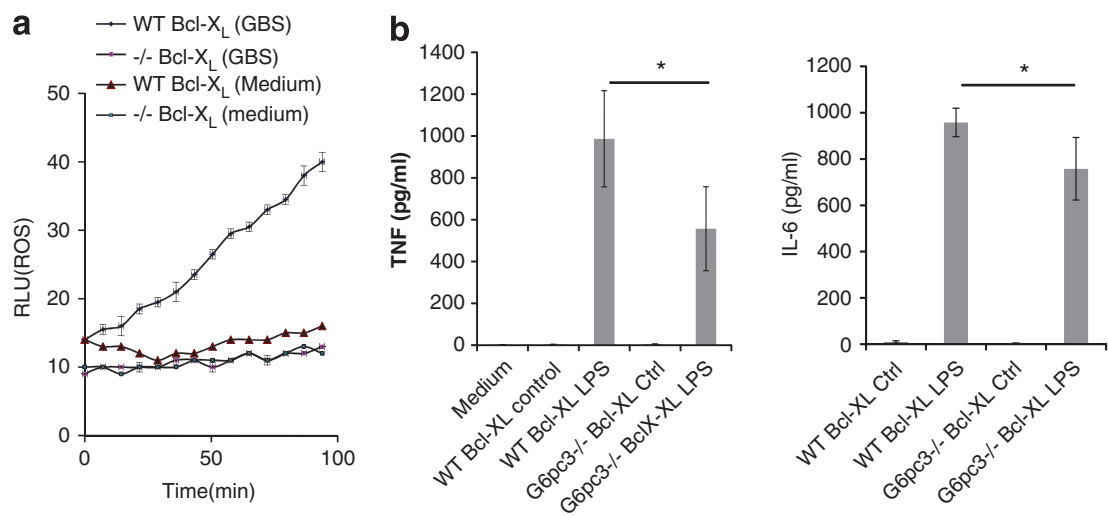

C
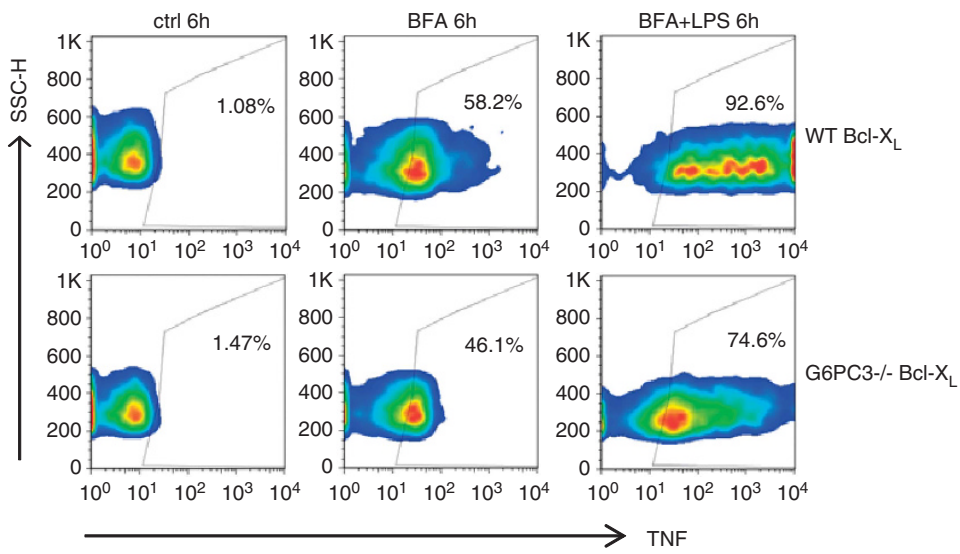

d

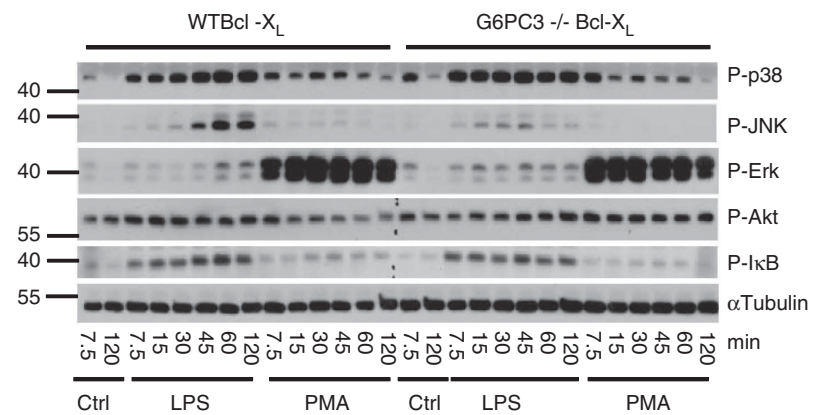

Figure 4 Functional defects in G6PC - I - neutrophils. (a) Reactive oxygen species (ROS) production by wt-Bcl- $\mathrm{X}_{\mathrm{L}}$ or G6PC3-Bcl- $\mathrm{X}_{\mathrm{L}}$ neutrophils stimulated with group B streptococcus (GBS). (b) Reduced cytokine secretion by G6PC3 ${ }^{-1-}$ neutrophils. Wild-type and G6PC3-Bcl-X differentiated (day 4) neutrophils were stimulated with $1 \mu \mathrm{g} / \mathrm{ml}$ LPS for $16 \mathrm{~h}$ and cytokines were measured in supernatants by ELISA. (c) Intracellular TNF-staining of differentiated wt-Bcl- $X_{L}$ or G6PC3-Bcl- $X_{L}$ neutrophils stimulated with $1 \mu \mathrm{g} / \mathrm{ml}$ LPS in the presence of brefeldin A for $6 \mathrm{~h}$. (d) Western blot showing phosphorylation of p38, JNK, Erk, Akt and IKB in wt-Bcl- $X_{L}$ or G6PC3-Bcl- $X_{L}$ differentiated neutrophils (day 4) stimulated with $1 \mu \mathrm{g} / \mathrm{ml}$ LPS or $1 \mu \mathrm{M}$ phorbol-myristate-acetate (PMA) for the times indicated. Data are representative of three (a), four (b), three (c) and two (d) independent experiments. Statistical significance was calculated using $t$-test; ${ }^{*} P<0.05$.

$\mathrm{BH} 3-$ only proteins are the triggers of mitochondrial apoptosis, and (based on the phenotypes of gene-deficient mice) Bim is the most important BH3-only protein in the hematopoietic system. To investigate the role of Bim, its expression was reduced by lentiviral delivery of Bim-specific shRNA in $\mathrm{G}_{6 \mathrm{PC}} 3^{-1-}$ progenitor cells. These cells were strongly protected against cell death during differentiation (Figure 5d), suggesting that increased expression of Bim has an important role in the enhanced apoptosis in $\mathrm{G}_{6 \mathrm{PC}}{ }^{-1-}$ cells during differentiation.

Bim can be induced by ER stress, ${ }^{25}$ and G6PC3-deficient patients and $\mathrm{G}_{6 \mathrm{PC}}{ }^{-1-}$ mouse neutrophils show enhanced expression of ER-stress markers. ${ }^{10,14} \mathrm{G} \mathrm{PC} 3^{-/-}-\mathrm{Bcl}-\mathrm{X}_{\mathrm{L}}$ cells also showed enhanced expression of the ER-stress marker glucose-regulated protein $78 \mathrm{kDa}$ (Grp-78) during differentiation (Figure 5e). The cause of ER stress in $\mathrm{G}_{6 \mathrm{PC}}{ }^{-1-}$ cells is not entirely clear but a deficiency in $\mathrm{N}$-linked glycosylation has been demonstrated in G6PC3deficient cells recently, ${ }^{26}$ and disturbances of this process are known to induce ER stress. ${ }^{27}$ Treatment with the inhibitor of $\mathrm{N}$-glycosylation, tunicamycin, caused a strong upregulation of Bim protein and mRNA as well as Grp-78 in wt-BclX progenitor cells (Figure $5 f$ ) and reduced proliferation of differentiating cells (Figure $5 \mathrm{~g}$ ), mirroring the phenotype of 
a

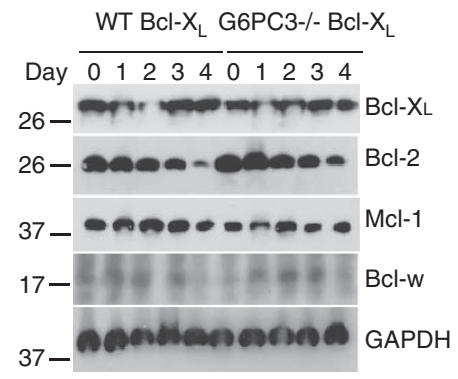

C

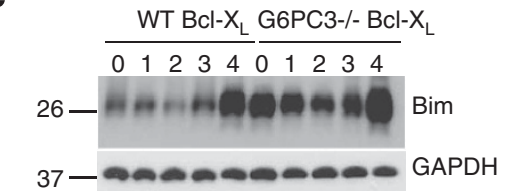

e

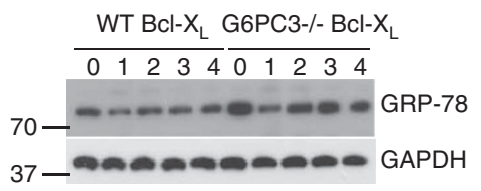

b $\quad$ WT BCl-X $\mathrm{X}_{\mathrm{L}}$ G6PC3-/- Bcl- $\mathrm{X}_{\mathrm{L}}$

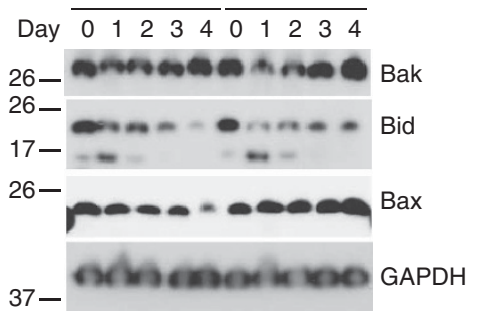

d

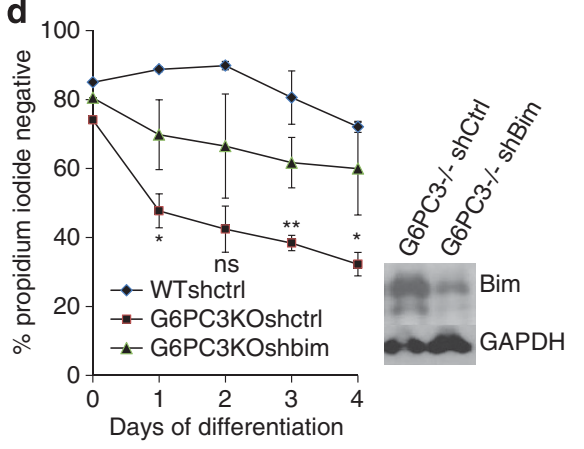

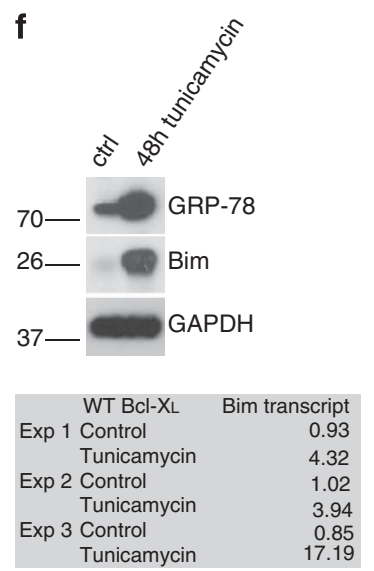

g

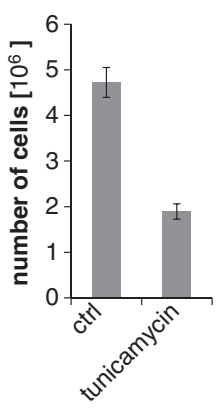

h glucose $\frac{\text { WT Bcl }}{+-}$

Figure 5 Induction of $\mathrm{ER}$ stress and role of Bim in $\mathrm{G}_{6 \mathrm{PC}}{ }^{-1}$ - cells. Wt-Bcl- $\mathrm{X}_{\mathrm{L}}$ and $\mathrm{G} 6 \mathrm{PC} 3-\mathrm{Bcl}-\mathrm{X}_{\mathrm{L}}$ were harvested on different days of differentiation and probed by western blot for (a) Bcl- $\mathrm{XL}_{\mathrm{L}}$ (transgene), Bcl-2, Mcl-1, Bcl-w; (b) Bak, Bax, Bid; (c) Bim and (e) GRP-78. (d) Cell death analysis (propidium iodide staining) of wild-type cells expressing control shRNA (shControl), and G6PC3 ${ }^{-1-}$ cells expressing control (shControl) or Bim-specific shRNA (shBim) different days of differentiation. ${ }^{*, * *}$ Values of shBim versus shCtrl are statistically significant $\left({ }^{*} P<0.05\right.$; ${ }^{* *} P<0.01$ ). Inset shows western blot analysis of Bim knock-down in G6PC3 ${ }^{-I-}$ progenitors. (f) Western blot shows expression of GRP-78 and Bim in wt-Bcl-X $X_{L}$ cells differentiated by estrogen withdrawal for 2 days in the presence or absence of $1 \mu \mathrm{g} / \mathrm{ml}$ tunicamycin. Table gives quantitative results of Bim transcripts upon the same treatment in three experiments (standardized to wild-type progenitor cells). (g) Numbers of wt-Bcl- $X_{L}$ cells obtained on day 2 of differentiation in the presence or absence of tunimycin $(1 \mu \mathrm{g} / \mathrm{ml})$. (h) Western blot showing expression of Bim and Mcl-1 in wt-Bcl- $\mathrm{X}_{\mathrm{L}}$ neutrophils differentiated for 4 days in complete medium or in the absence of glucose. Two different exposure times are shown for better appreciation of both Bim $\mathrm{EL}_{\mathrm{L}}$ and Bim $\mathrm{L}_{\mathrm{L}}$ GAPDH served as loading control in all western blots. Data are representative of three independent experiments. Error bars represent standard deviation. Statistical significance was calculated using t-test. ${ }^{*} P<0.05,{ }^{* *} P<0.01,{ }^{* * *} P<0.001$. ns, non-significant $(P>0.05)$

$\mathrm{G} 6 \mathrm{PC}^{-1-}$ cells (Figures $5 \mathrm{c}$, e and $3 \mathrm{a}$ ). It is therefore likely that Bim induction and apoptosis in $\mathrm{G} 6 \mathrm{PC} 3^{-1-}$ cells are the result of ER stress. Culture in low-glucose medium caused the upregulation of Grp-78 and Bim (Figure 5h), supporting the notion that ER stress is linked to low-glucose availability in $\mathrm{G}_{\mathrm{CPC}}{ }^{-1-}$ cells.

A number of neutrophil proteins pass through the ER and are stored in granules before secretion. One such group is serine proteases with effector functions. To test how ER stress in $\mathrm{G}_{6 \mathrm{PC}}{ }^{-1-}$ cells affects protease secretion, we assessed the levels of a major serine protease, NE, during differentiation. The pattern of expression of NE in wt cells was as expected, namely high levels of expression at earlier stages and downregulation during differentiation (Figure 6a). Expression was substantially reduced in $\mathrm{G} 6 \mathrm{PC}^{-l-}-\mathrm{Bcl}-\mathrm{X}_{\mathrm{L}}$ cells compared with wt-Bcl- $X_{L}$ cells (Figure $6 a$ ). Much less NE was found in the culture supernatant of $\mathrm{G}_{\mathrm{PPC}}{ }^{-1-}-\mathrm{Bcl}-\mathrm{X}_{\mathrm{L}}$ neutrophils compared with wt-Bcl- $X_{L}$ cells (Figure $6 b$ ). Treatment with tunicamycin also massively reduced the protein levels of NE in wt-Bcl- $X_{L}$ cells (Figure $6 \mathrm{c}$ ). The mRNA levels of NE in $\mathrm{G} \mathrm{PC} 3^{-1-}-\mathrm{BCl}-\mathrm{X}_{\mathrm{L}}$ cells reflected the protein levels in that they were severely reduced at all stages 
a

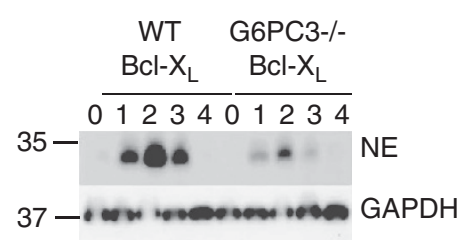

b culture supernatant

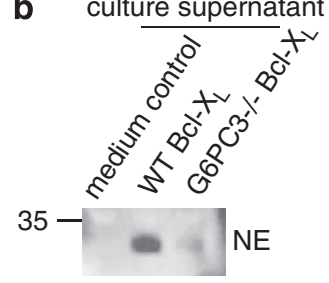

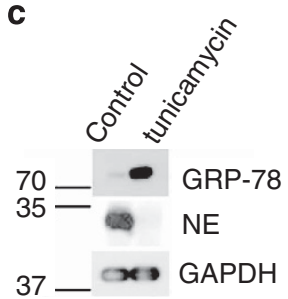

Figure 6 Downregulation of neutrophil elastase (NE) in $\mathrm{G}_{6 \mathrm{PC}}{ }^{-1-}$ cells and by ER stress. (a) Western blot showing expression levels of NE in differentiating wt-Bcl- $\mathrm{X}_{\mathrm{L}}$ and G6PC3-Bcl- $X_{L}$ cells. (b) Western blot analysis of NE in day 4 culture supernatant from wt-Bcl- $X_{L}$ and $G 6 P C 3-B c l-X_{L}$ cells. (c) Western blot analysis showing expression of $\mathrm{NE}$ in wt-Bcl- $\mathrm{X}_{\mathrm{L}}$ cells differentiated for 2 days in the presence or absence of tunicamycin $(1 \mu \mathrm{g} / \mathrm{ml})$. Data are representative of two independent experiments

(Supplementary Figure 3). Treatment with tunicamycin almost abolished NE mRNA expression (Supplementary Figure 3B). Surprisingly, treatment with tunicamycin did not affect the secretion of TNF or IL-6 (S2). These data suggest that ER stress can regulate the expression of NE and this in turn may be a cause of reduced NE in G6PC3 ${ }^{-1-}$ neutrophils.

The differentiation system of Hoxb8 cells in vitro in the presence of SCF recapitulates at least the majority of the known features of neutrophil maturation. However, it is likely that bone marrow niches will provide additional soluble and membrane-bound stimuli that further aid and direct differentiation. We therefore endeavored to establish a system where we could test differentiation of Hoxb8 cells in vivo.

This was achieved by using adoptive transfer of Hoxb8 cells into irradiated mice. Mice were irradiated with a myeloablative dose and reconstituted with syngeneic bone marrow. With these bone marrow cells, Hoxb8-derived neutrophil progenitor cells were co-transplanted at a ratio of $10: 1$ of Hoxb8 cells to bone marrow cells. To trace the cells, progenitor lines were retrovirally transduced with a vector expressing EGFP.

Low numbers of green fluorescent protein (GFP)-positive cells were seen in peripheral blood on day 4 post transplantation (Supplementary Figure 4C). The highest numbers were found on day 6; on day 8 only few cells were detectable (Supplementary Figure 4C). Day 6 was therefore chosen for further analysis.

About $60 \%$ of live leucocytes in peripheral blood of mice transplanted with wt Hoxb8-progenitor cells expressed GFP (i.e., were derived from Hoxb8 cells). A total of $60 \%$ of mature neutrophils in peripheral blood were GFP positive (Figure 7b). In the bone marrow, these numbers were lower at this time point (GFP-positive cells made up about $20 \%$ of all cells, and of this GFP-positive population, mature neutrophils represented about $40 \%$ Figure $7 \mathrm{~b}$ ). In comparison, only very few Hoxb8-derived cells were detectable when $\mathrm{G} \mathrm{PC} 3^{-1-}$ cells were transplanted (Figures $7 a$ and $b$ ).

When wt-Bcl- $X_{L}$ progenitor cells were transplanted, the proportion of Hoxb8-derived (GFP-positive) cells dropped somewhat (Figure 7c); this may be due to the reported antiproliferative effect of $\mathrm{Bcl}-2$-proteins. ${ }^{28}$ However, $\mathrm{Bcl}-\mathrm{X}_{\mathrm{L}}$ expression was able to support differentiation of $\mathrm{G}_{6 \mathrm{PC}} 3^{-1-}$ cells: the proportion of $\mathrm{G} 6 \mathrm{PC} 3^{-1-}-\mathrm{Bcl}-\mathrm{X}_{\mathrm{L}}$ neutrophils reached about half of the proportion of wt-Bcl- $X_{L}$ neutrophils, both in bone marrow and in peripheral blood (Figures 7c and d).

About two-third of the GFP-positive cells in peripheral blood were mature neutrophils (Gr-1 and CD11b high). The remainder were largely CD11b-positive, Gr-1-low, immature neutrophils (we will refer to these two populations as mature and immature neutrophils; Figure $8 \mathrm{a}$ ). These ratios of the two populations are similar to those seen in peripheral blood of non-irradiated wt mice (Supplementary Figure 4). In the bone marrow of transplanted mice, these two populations were also detected although the proportion of immature neutrophils on day 6 was higher in the Hoxb8derived (GFP-positive) population (Figure 8a). Very few Hoxb8-derived cells were detected in the peripheral blood of mice transplanted with G6PC3 ${ }^{-1-}$ cells (Figures $8 \mathrm{a}$ and $7 \mathrm{~b}$ ). Although more cells were detectable in bone marrow, they largely appeared immature by the markers CD11b and Gr-1 (Figure 8a).

When $\mathrm{Bcl}-\mathrm{X}_{\mathrm{L}}$-expressing Hoxb8 progenitors were transplanted, GFP-expressing wt and $\mathrm{G} 6 \mathrm{PC} 3^{-1}$ cells were found in bone marrow, spleen and peripheral blood. Surprisingly, unlike wt and wt-Bcl- $X_{L}$ cells, $\mathrm{G}_{6 \mathrm{PC}}{ }^{-1-}-\mathrm{Bcl}-\mathrm{X}_{\mathrm{L}}$ cells appeared to produce almost exclusively mature (CD11b/Gr1-high) cells in all three compartments (Figures $8 \mathrm{c}$ and $\mathrm{d}$ ). Morphologically, these cells appeared fully mature, distinctly more so than cells differentiated in vitro (Figures $8 c$ and $3 b$ ). However, the ability of bone marrow-localized $\mathrm{G}_{6 \mathrm{PC}}{ }^{-1}$ -Bcl- $X_{L}$ cells to produce TNF (Figure 8 e) and IL-6 (not shown) was still limited, similarly to in vitro differentiated $\mathrm{G}_{6 \mathrm{PC}}{ }^{-/-}$ -Bcl- $X_{L}$ cells (Figure 4c).

In searching for an explanation for the presumably faster maturation of $\mathrm{G}_{6 \mathrm{PC}}{ }^{-/-}-\mathrm{Bcl}-\mathrm{X}_{\mathrm{L}}$ cells in vivo, we noticed that these cells in the bone marrow on day 6 post transplantation expressed normal levels of CXCR4 and CXCR2 but reduced levels of c-kit, the receptor of SCF (Supplementary Figure 5A). This downregulation may be the result of the reduced cytosolic glucose due to the defect in G6PC3: culture in low-glucose medium caused a reduction in c-kit-expression in wt cells (Supplementary Figure 5B). C-kit downregulation may in turn be linked to the accelerated expression of maturation markers in $\mathrm{G}_{6 \mathrm{PC}} 3^{-1-}-\mathrm{BCl}-\mathrm{X}_{\mathrm{L}}$ cells. Culture of wt-Bcl- $X_{L}$ cells in the absence of SCF (mimicking loss of its receptor c-kit) also accelerated maturation of the cells, by both surface marker analysis and morphology (Supplementary Figure 5C, D). Low cytosolic glucose, by downregulating c-kit, may at least contribute to the faster maturation, if apoptosis is inhibited at the same time.

The Hoxb8 system can also be used to generate macrophage progenitor lines. ${ }^{18}$ We established $\mathrm{G} \mathrm{PC} 3^{-/-}$ macrophage progenitor lines and differentiated macrophages from these cell lines in vitro. A recent report demonstrates certain defects in chemotaxis, respiratory burst and 
a

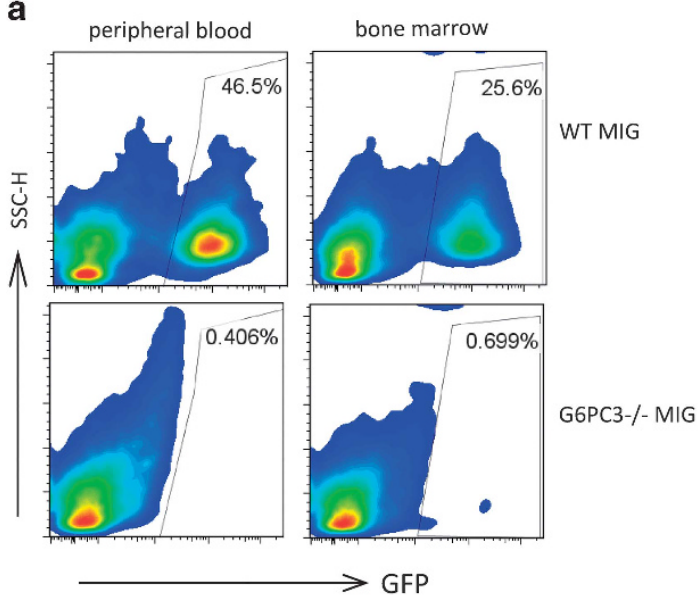

c

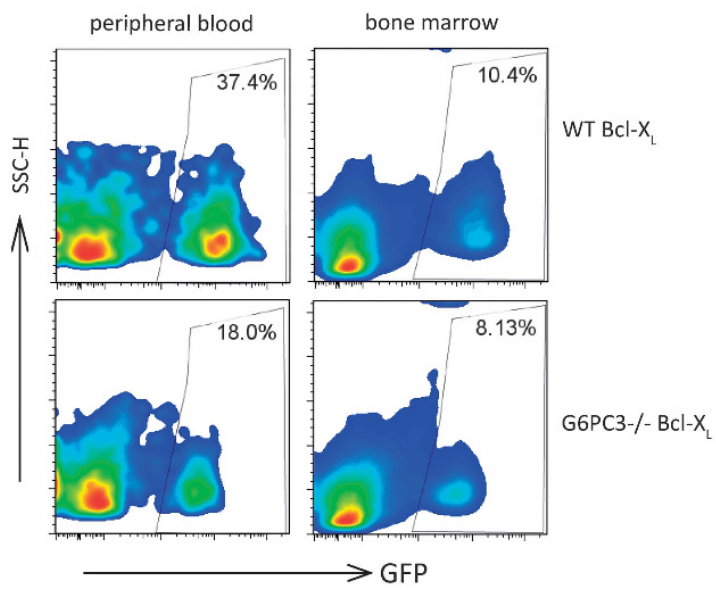

b
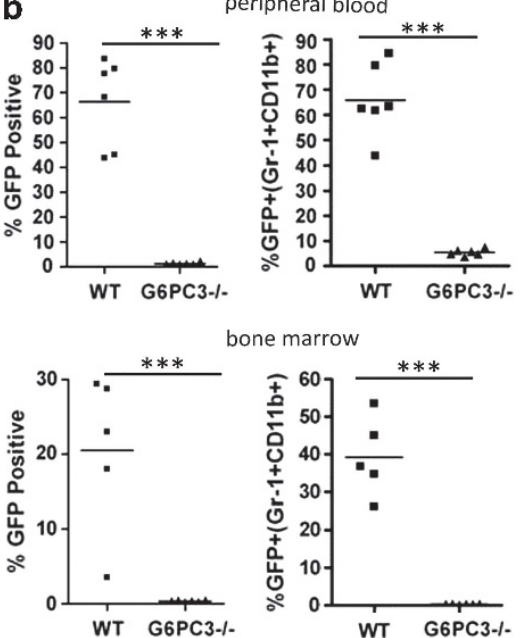

d
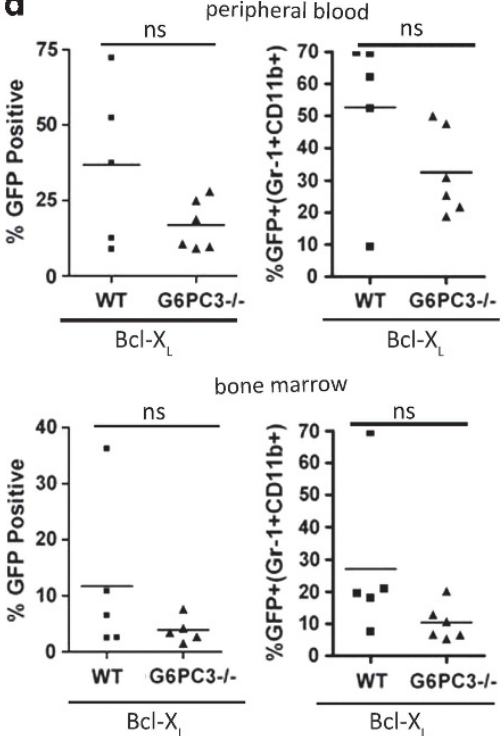

Figure 7 In vivo differentiation of Hoxb8 cells. (a) Flow cytometry analysis of peripheral blood and bone marrow of mice on day 6 after transplantation of irradiated mice with wild-type or G6PC3-deficient Hoxb8-progenitor cells expressing GFP under a retroviral promoter. Cells in a total live cell gate are shown. (b) Percentages of GFP-positive populations (\%GFP-positive of total live cells) and percentage of GFP-positive cells of total live Gr-1-high and CD11b-high (Gr1 + CD11b + ) cells in mice transplanted with GFP-expressing Hoxb8-progenitors (day 6). (c) Percentages of GFP-positive populations (\%GFP-positive of total live cells) in peripheral blood and bone marrow on day 6 of mice transplanted with $\mathrm{Bcl}-\mathrm{X}_{\mathrm{L}}$-expressing wild-type or $\mathrm{G}_{\mathrm{CPC}}{ }^{-1}$ - Hoxb8-progenitors (cells were transduced with the retroviral plasmid pMIG-BclX $\mathrm{L}_{\mathrm{L}}$, which drives $\mathrm{GFP}$ off an IRES). (d) Percentages of GFP-positive populations (\%GFP-positive of total live cells) and percentage of GFP-positive cells of total live Gr-1-high and CD11b-high $(\mathrm{Gr} 1+\mathrm{CD} 11 \mathrm{~b}+)$ cells in mice transplanted with Bcl-X/GFP-expressing Hoxb8-progenitors (day 6). Data were obtained from two independent experiments with three or two mice in each group. Each symbol represents one mouse. Statistical significance was calculated by $t$-test. ${ }^{* \star *} P<0.001$; ns, non-significant $(P>0.05)$

phagocytosis in primary macrophages from $\mathrm{G}_{\mathrm{PPC}}{ }^{-1-}$ mice. ${ }^{29}$ There was no obvious survival (Supplementary Figure 6A) or morphological defect (Supplementary Figure 6B) in differentiating Hoxb8-macrophages, although fewer cells were obtained at the end of differentiation (day 8) (Supplementary Figure $6 \mathrm{C}$ ) and differentiated cells had slightly lower levels of F4/80 (Supplementary Figures 6D, E). In response to LPS, G6PC3 ${ }^{-1-}$ macrophages produced normal levels of IL-6 (Supplementary Figure S6F) and somewhat reduced levels of TNF (Supplementary Figure 6G); they further showed a reduced capacity for oxidative burst upon stimulation with zymosan (Supplementary Figure 6H). The defect in neutrophils appears strikingly more pronounced upon loss of G6PC3 than in macrophages, consistent with the findings in humans and in gene-deficient mice. ${ }^{14,29}$

\section{Discussion}

We here describe the use of a neutrophil differentiation model to analyze defects caused by the loss of G6PC3 in mouse hematopoietic cells. The use of this model permitted a separation of enhanced cell death susceptibility and of differentiation defects and enabled us to test some of the molecular events leading to the observed deficiencies. The model is also suited to test for defects in macrophages. 
a

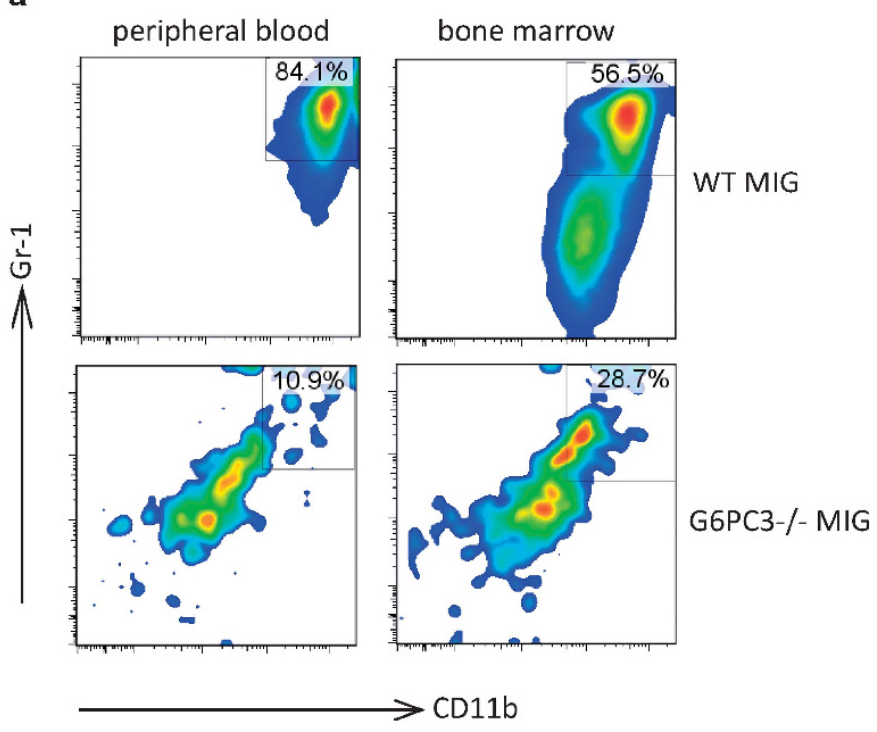

b peripheral blood

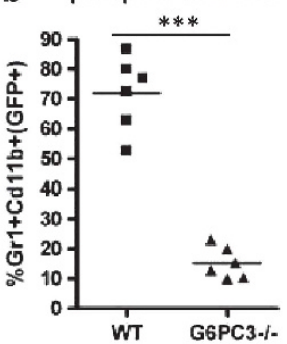

bone marrow

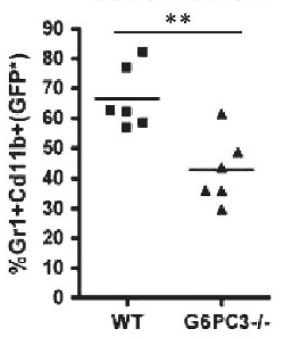

c

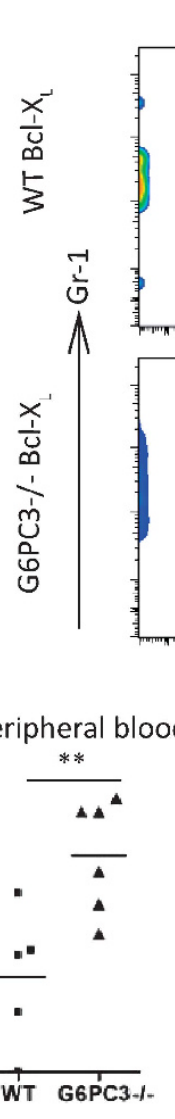

$\mathrm{Bcl}-\mathrm{X}$

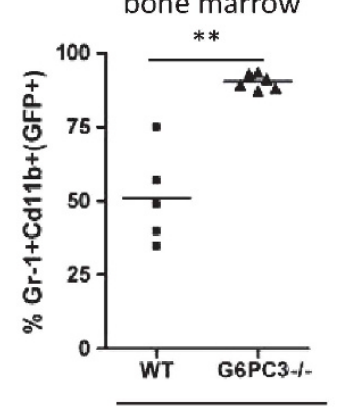

$\mathrm{Bcl}-\mathrm{X}$ peripheral blood

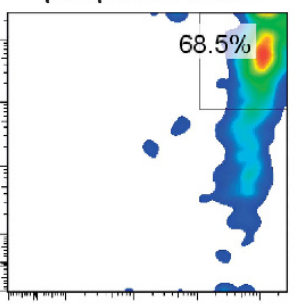

bone marrow
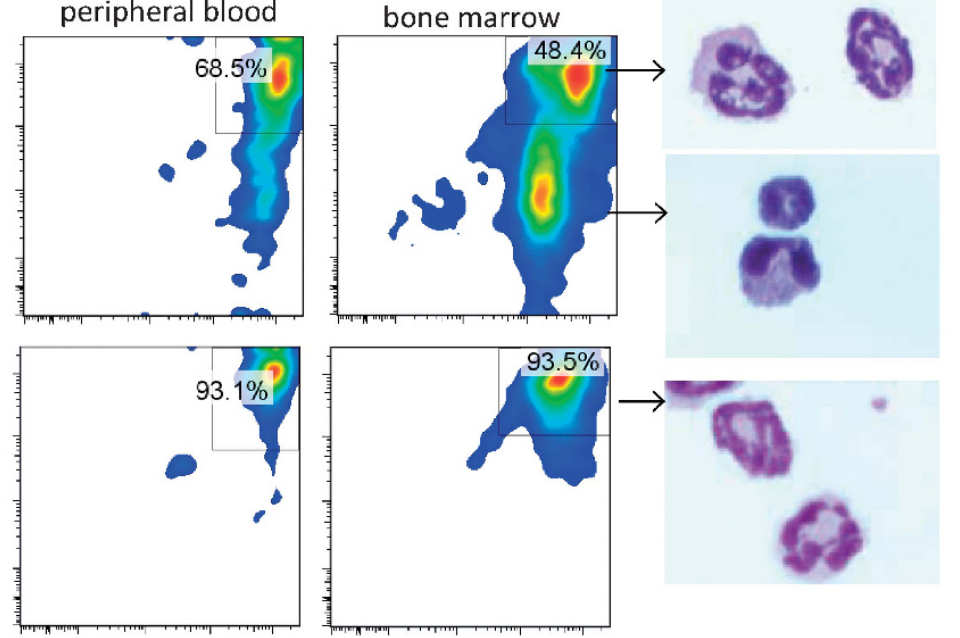

$\mathrm{CD} 11 \mathrm{~b}$

e

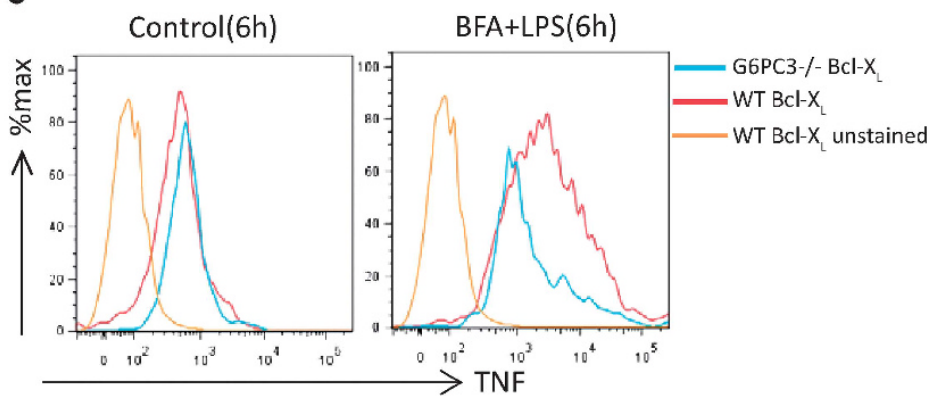

Figure 8 In vivo maturation of wild-type and $\mathrm{G} 6 \mathrm{PC} 3^{-1-}$ cells. (a and $\left.\mathbf{b}\right)$ Day 6 flow cytometry data showing Gr1-high and CD11b-high populations in peripheral blood and bone marrow of mice transplanted with wild-type or G6PC3 ${ }^{-1}$ Hoxb8 progenitor cells (gated on GFP-positive cells). (c and d) Day 6 flow cytometry data showing Gr1- and $\mathrm{CD11b}$-expression in spleen, peripheral blood and bone marrow of mice transplanted with wt-Bcl- $\mathrm{X}_{\mathrm{L}}$ or G6PC3-Bcl-X $\mathrm{X}_{\mathrm{L}}$ Hoxb8 progenitor cells (gated on GFP-positive cells). Right, cells were sorted from bone marrow of mice day 6 after transplantation and stained with Giemsa (magnification $\times 630$ ). (e) Bone marrow cells from mice transplanted with wt-Bcl- $X_{L}$ or G6PC3-Bcl-X $X_{L}$ Hoxb8 progenitor cells were stimulated for $6 \mathrm{~h}$ with $1 \mu \mathrm{g} / \mathrm{ml}$ LPS in the presence of brefeldin A (BFA); day 6 after transplantation; cells were gated for GFP-positivity. Data are representative of two independent experiments with three or two mice in each group except (e), where flow cytometry histograms represent similar results obtained from three mice. Statistical significance was calculated using $t$-test. ${ }^{* *} P<0.01,{ }^{* \star *} P<0.001$ 
However, in macrophages, the effects of the loss of G6PC3 were only moderate, confirming a recent report. ${ }^{29}$

G6PC3 is located in the ER, and its deficiency decreases the shuttling of glucose to the cytosol, with a shortage of cytosolic glucose and associated changes in carbohydrate metabolism. ${ }^{15}$ Defects in protein $\mathrm{N}$ - (and $\mathrm{O}$-) glycosylation have also recently been identified in these cells. ${ }^{26} \mathrm{ER}$ stress occurs upon glucose starvation; ${ }^{30}$ this may be a consequence of the reduction of $\mathrm{N}$-glycosylation. ${ }^{27}$

ER stress is a known inducer of apoptosis. ${ }^{27}$ The precise mechanism of ER stress-induced apoptosis is still in part uncertain but the pro-apoptotic Bcl-2-family member, the BH3only protein $\mathrm{Bim}$, has been found to be prominently involved. ${ }^{25}$ We found that Bim levels are upregulated in $\mathrm{G} \mathrm{PC} 3^{-1}$ cells throughout differentiation, and Bim-specific RNAi substantially reduced apoptosis. There was also an increase in the levels of Bax, especially in mature $\mathrm{G} 6 \mathrm{PC} 3^{-1-}$ neutrophils, as reported recently in neutrophils isolated from $\mathrm{G} 6 \mathrm{PC} 3^{-1-}$ mice. ${ }^{16} \mathrm{We}$ also observed a reduction in the levels of the anti-apoptotic protein $\mathrm{Mcl}-1$, confirming earlier results. ${ }^{10}$

Inhibition of apoptosis by $\mathrm{BCl}-\mathrm{X}_{\mathrm{L}}$ permitted the search for further defects in G6PC3 ${ }^{-1-}$ cells, and defects in morphological maturation and production of effector proteins (cytokines, NE) were observed. The loss of all of them is likely to contribute to a loss of function of G6PC3 $3^{-1-}$ cells, on top of the apoptosis-mediated neutropenia.

These biological effects are probably the result of first a reduction of cytosolic glucose levels and of glycolytic energy generation and second, as a consequence, ER stress and the unfolded protein response. Experimental glucose withdrawal or pharmacological blockade of $\mathrm{N}$-linked glycosylation induced ER stress, loss of NE and apoptosis in wt cells, similar to the events seen in G6PC3 ${ }^{-1-}$ cells.

During in vitro differentiation from Hoxb8 progenitors, the cells depend on SCF for their survival. Although this is sufficient for phenotypic and functional maturation of neutrophils, SCF signals will very likely, not completely, represent the bone marrow niche where neutrophils develop during normal differentiation. In the bone marrow, G-CSF signals probably also have a role. ${ }^{31}$ Further, additional signals are also available in the bone marrow, for instance chemokines. The sum of these signals probably provides a better microenvironment for the differentiation of neutrophils.

This difference became clearly apparent when G6PC3$\mathrm{BCl}-\mathrm{X}_{\mathrm{L}}$ cells were transplanted into irradiated mice: the recovered cells were morphologically more mature, and the tendency toward more complete high-level expression of $\mathrm{Gr}-1$ and a reduction in c-kit expression were more pronounced in cells differentiated in vivo. C-kit was in vitro and in vivo downregulated substantially faster in G6PC3-Bcl- $X_{L}$ cells compared with wt, and taking away SCF from wt-Bcl- $X_{L}$ cells in vitro accelerated maturation. C-kit signaling may therefore indeed slow down maturation of differentiating neutrophils.

We believe that this model of Hoxb8-mediated generation of neutrophil progenitors is a step toward easier, detailed analysis of human neutropenia. Unlimited generation of cells, easy genetic manipulation and the analysis of differentiating cells in vitro are substantial advantages over the experimental options of analysis in human samples and even in gene-deficient mice. The cells can further be tested in the absence of the stressed environment of a human patient or a gene-deficient mouse. Although the differentiation that can be achieved in vitro by the use of SCF appears incomplete in some ways, the option of letting the cells differentiate in the myelopoietic niches of bone marrow of mice permits the restoration of differentiation in a near-natural environment. This model should therefore be of significant use to explore the molecular and cellular causes of human immunodeficiency and to devise therapeutic approaches to such disorders.

\section{Materials and Methods}

Cell lines. Hoxb8 progenitors were established from bone marrow of wt and G6PC-deficient mouse C57B//6 littermates as described. ${ }^{18,19}$ Polyclonal cell lines were established by retroviral transduction of Hoxb8 and selected in the presence of SCF (neutrophil precursors) or granulocyte-macrophage colony-stimulating factor (macrophage precursors). Precursor cell lines were cultured in Optimem medium (Invitrogen, Karlsruhe, Germany) supplemented with 10\% FCS, $30 \mathrm{mM}$ $\beta$-mercaptoethanol, antibiotics, $1 \%$ supernatant from SCF-producing Chinese hamster ovary cells or granulocyte-macrophage colony-stimulating factorproducing B16 melanoma cells and $1 \mu \mathrm{M}$ estrogen. Differentiation was induced by removal of estrogen. ${ }^{18}$

Apoptosis assays. Cells were washed in PBS $10 \%$ FCS, then with Annexin V-binding buffer (10 mM HEPES, $140 \mathrm{mM} \mathrm{NaCl}, 2.5 \mathrm{mM} \mathrm{CaCl}_{2}$ ) and incubated with Annexin V-APC and propidium iodide followed by flow cytometry. For analysis of caspase-3 activation, $48 \mathrm{~h}$ progenitor cultures were washed with PBS, fixed in $3.7 \%$ formaldehyde and permeabilized with $0.5 \%$ Saponin (Sigma, Munich, Germany). Staining was performed with rabbit anti-active caspase-3 (BD Pharmingen, Heidelberg, Germany) in PBS $/ 0.5 \%$ BSA for $20 \mathrm{~min}$ at room temperature, followed by incubation with anti-rabbit-Cy5 (Dianova, Hamburg, Germany) for $30 \mathrm{~min}$ and samples were analyzed by flow cytometry.

RNA extraction. RNA was extracted and cDNA was synthesized using commercially available kits (Roche, Mannheim, Germany). Samples were analyzed by quantitative RT-PCR using the Light Cycler Taqman Master kit and the Universal Probe Library system. Normalization was done to $\beta$-actin. For analysis of serine protease mRNA, the signals were quantified by gel densitometry analysis of RT-PCR product using ImageJ (reference GAPDH).

Immunoblotting. Cells were washed with PBS and directly lysed in Laemmli buffer $\left(3 \times 10^{6}\right.$ cells $\left./ 50 \mu l\right)$ and boiled at $95^{\circ} \mathrm{C}$ for $5 \mathrm{~min}$. Cell extracts were separated by SDS-PAGE and proteins were transferred to PVDF membranes. Antibodies used were specific for: Bim, Bcl- $X_{L}, B c l-w, B a x$, GRP-78, phosphorylated p38, phosphorylated JNK, phosphorylated Erk, phosphorylated Akt and phosphorylated IKB antibodies (all from Cell Signaling Technology, Beverley, MA, USA), Bak, GAPDH (Millipore, Schwalbach, Germany), Bcl-2 (BD Pharmingen), Mcl-1 (Rockland, Gilbertsville, PA, USA), NE (Santa Cruz Biotechnology, Inc. ,Santa Cruz, CA, USA) or tubulin (Sigma). Peroxidaseconjugated secondary antibodies against rabbit (Sigma), mouse (Dianova), rat (Dianova) or hamster (Dianova) and an enhanced chemoluminescence detection system (GE Healthcare, Munich, Germany) were used.

Flow cytometry. Cells were stained with anti-Gr-1-APC, anti-CD11b-PE, anti-c-kit-APC, anti-CXCR-2-APC or anti-CXCR-4-APC (all from BD bioscience, San Jose, CA, USA except anti-CXCR-2 (Biolegend, San Diego, CA, USA)). Fc blocking antibody was from $\mathrm{BD}$ bioscience.

Giemsa stain. Mouse peripheral blood smear or Hoxb8 neutrophils (following cytospin) were stained by Giemsa solution (Merck, Darmstadt, Germany).

Retroviral transduction of neutrophil precursor lines. Empty vector or MIGR1-GW-BCl-XL-IRES-EGFP retroviral vector was packaged by transient transfection of the retroviral expression plasmid together with the packaging plasmid pCLEco into the Phoenix cell line. Supernatant was collected and filtered through a $0.45-\mu \mathrm{m}$ membrane and was used to infect Hoxb8 neutrophil progenitors in the presence of $5 \mu \mathrm{g} / \mathrm{ml}$ polybrene. Cells were sorted for GFP expression. 
Lentiviral transduction. Lentiviruses carrying Bim-specific shRNA or control shRNA ${ }^{32}$ were produced by transient transfection of these vectors together with packaging plasmids psPAX2 and pMD2.G into HEK 293 FT cells (Invitrogen). Supernatants were filtered through $0.45-\mu \mathrm{m}$ membranes and used to transduce Hoxb8 neutrophil progenitors in the presence of $5 \mu \mathrm{g} / \mathrm{ml}$ polybrene. GFP-positive cells were sorted.

Neutrophil effector functions. For ELISA, $1 \times 10^{6}$ differentiated Hoxb8 cells were stimulated with $1 \mu \mathrm{g} / \mathrm{ml}$ LPS. Cytokines in supernatants were quantified using ELISA kits (eBioscience, San Diego, CA, USA). For intracellular staining, cells were pretreated with $1 \mu \mathrm{l} / \mathrm{ml}$ golgiplug (BD Bioscience) for $1 \mathrm{~h}$ and stimulated with $1 \mu \mathrm{g} / \mathrm{ml}$ LPS for $6 \mathrm{~h}$. Cells were fixed in $4 \%$ formaldehyde, permeabilized by saponin and stained with APC-labeled antibody against TNF. To measure reactive oxygen species production, $1 \times 10^{5}$ differentiated cells were treated with lucigenin and simultaneously stimulated with serum-treated zymosan. The reaction product was measured by luminometry (Fusion Fx, Perkin Elmer, Santa Clara, CA, USA). To estimate glucose levels, $1 \times 10^{6}$ progenitor cells were cultured for $48 \mathrm{~h}$ in $3 \mathrm{ml}$ medium. Cell-free supernatant was harvested and glucose was estimated using the hexokinase method. Hexokinase (Roche), $\mathrm{MgCl}_{2}$, ATP, NADP and glucose (all from Sigma) were used for the reaction and measurement was done in lambda 14 UV/VIS spectrometer (Perkin Elmer). For the 2-deoxy glucose (2DG) uptake assay, $1 \times 10^{6}$ progenitor cells were incubated for $15 \mathrm{~min}$ in $0.5 \mu \mathrm{Ci}$ tritium-labeled 2DG (Perkin Elmer) and $6.5 \mathrm{mM}$ unlabeled 2DG (Sigma). Reaction was stopped with cold PBS and cell pellets were washed four times at $4{ }^{\circ} \mathrm{C}$. After lysing cell pellets with $0.1 \%$ SDS, the radioactivity was determined in beta counter in liquid scintillation cocktail fluid (Ultima Gold, Perkin Elmer). ${ }^{33}$

Adoptive transfer of Hoxb8 progenitor cells. A total of $5 \times 10^{6} \mathrm{Hoxb8}$ progenitor cells were mixed with $5 \times 10^{5}$ bone marrow cells and transplanted into syngeneic mice $24 \mathrm{~h}$ after lethal irradiation $(2 \times 5 \mathrm{~Gy})$ by injection into the tail-vein.

\section{Conflict of Interest}

The authors declare no conflict of interest.

Acknowledgements. This work was supported by the Deutsche Forschungsgemeinschaft (DFG) through a grant to GH (SFB 620/A17), and SG was supported by the Excellence Initiative of the German Federal and State Governments (GSC-4, Spemann Graduate School). HH was supported by the American Lebanese Syrian Associated Charities (ALSAC). IEG was funded by an EMBO LTF. We thank Dr. Richard O'Brien, Vanderbilt University Medical School, Nashville, for providing bone marrow from $\mathrm{G}_{6} \mathrm{PC} 3^{-1-}$ mice, Dr. Robert Zeiser, Hematology Freiburg, for help with in vivo experiments and Dr. Georg Kochs, Virology, Freiburg, for his generous help with the 2DG assay.

\section{Author Contributions}

Experiments were conceived and designed by GH, SG, SK, PH and HH. SG performed most experiments except mRNA analyses (LM and $A B$ ) and MAPK analysis (CK). IEG substantially contributed to conducting and analysing the in vivo experiments. The manuscript was written by GH and SG, the figures were made by SG. All authors provided detailed comments on the manuscript.

1. Klein C. Genetic defects in severe congenital neutropenia: emerging insights into life and death of human neutrophil granulocytes. Annu Rev Immunol 2011; 29: 399-413.

2. Kostmann R. Infantile genetic agranulocytosis; agranulocytosis infantilis hereditaria. Acta paediatrica 1956; 45(Suppl 105): 1-78.

3. Dale DC, Link DC. The many causes of severe congenital neutropenia. N Engl J Med 2009; 360: 3-5.

4. Chao JR, Parganas E, Boyd K, Hong CY, Opferman JT, Ihle JN. Hax1-mediated processing of HtrA2 by Parl allows survival of lymphocytes and neurons. Nature 2008; 452: 98-102.

5. Cavnar PJ, Berthier E, Beebe DJ, Huttenlocher A. Hax1 regulates neutrophil adhesion and motility through RhoA. J Cell Biol 2011; 193: 465-473.

6. Kollner I, Sodeik B, Schreek S, Heyn H, von Neuhoff N, Germeshausen M et al. Mutations in neutrophil elastase causing congenital neutropenia lead to cytoplasmic protein accumulation and induction of the unfolded protein response. Blood 2006; 108: 493-500.
7. Grenda DS, Murakami M, Ghatak J, Xia J, Boxer LA, Dale D et al. Mutations of the ELA2 gene found in patients with severe congenital neutropenia induce the unfolded protein response and cellular apoptosis. Blood 2007; 110: 4179-4187.

8. Lin B, Annabi B, Hiraiwa H, Pan CJ, Chou JY. Cloning and characterization of cDNAs encoding a candidate glycogen storage disease type $1 \mathrm{~b}$ protein in rodents. $\mathrm{J}$ Biol Chem 1998; 273: 31656-31660.

9. Guionie O, Clottes E, Stafford K, Burchell A. Identification and characterisation of a new human glucose-6-phosphatase isoform. FEBS Lett 2003; 551: 159-164

10. Boztug K, Appaswamy G, Ashikov A, Schaffer AA, Salzer U, Diestelhorst J et al. A syndrome with congenital neutropenia and mutations in G6PC3. N Engl J Med 2009; 360: $32-43$.

11. Xia J, Bolyard AA, Rodger E, Stein S, Aprikyan AA, Dale DC et al. Prevalence of mutations in ELANE, GFI1, HAX1, SBDS, WAS and G6PC3 in patients with severe congenital neutropenia. Br J Haematol 2009; 147: 535-542.

12. Arostegui Jl, de Toledo JS, Pascal M, Garcia C, Yague J, Diaz de Heredia C. A novel G6PC3 homozygous 1-bp deletion as a cause of severe congenital neutropenia. Blood 2009; 114: 1718-1719.

13. Banka S, Chervinsky E, Newman WG, Crow YJ, Yeganeh S, Yacobovich J et al. Further delineation of the phenotype of severe congenital neutropenia type 4 due to mutations in G6PC3. Eur J Hum Genet 2011; 19: 18-22.

14. Cheung YY, Kim SY, Yiu WH, Pan CJ, Jun HS, Ruef RA et al. Impaired neutrophil activity and increased susceptibility to bacterial infection in mice lacking glucose-6-phosphatasebeta. J Clin Invest 2007; 117: 784-793.

15. Jun HS, Lee YM, Cheung YY, McDermott DH, Murphy PM, De Ravin SS et al. Lack of glucose recycling between endoplasmic reticulum and cytoplasm underlies cellular dysfunction in glucose-6-phosphatase-beta-deficient neutrophils in a congenital neutropenia syndrome. Blood 2010; 116: 2783-2792.

16. Jun HS, Lee YM, Song KD, Mansfield BC, Chou JY. G-CSF improves murine G6PC3deficient neutrophil function by modulating apoptosis and energy homeostasis. Blood 2011; 117: 3881-3892.

17. McDermott DH, De Ravin SS, Jun HS, Liu Q, Priel DA, Noel P et al. Severe congenital neutropenia resulting from G6PC3 deficiency with increased neutrophil CXCR4 expression and myelokathexis. Blood 2010; 116: 2793-2802.

18. Wang GG, Calvo KR, Pasillas MP, Sykes DB, Hacker H, Kamps MP. Quantitative production of macrophages or neutrophils ex vivo using conditional Hoxb8. Nat Methods 2006; 3: 287-293.

19. Kirschnek S, Vier J, Gautam S, Frankenberg T, Rangelova S, Eitz-Ferrer P et al. Molecular analysis of neutrophil spontaneous apoptosis reveals a strong role for the pro-apoptotic BH3-only protein Noxa. Cell Death Differ 2011; 18: 1805-1814.

20. Borregaard N. Neutrophils, from marrow to microbes. Immunity 2010; 33: 657-670.

21. Wang Y, Oeser JK, Yang C, Sarkar S, Hackl SI, Hasty AH et al. Deletion of the gene encoding the ubiquitously expressed glucose-6-phosphatase catalytic subunit-related protein (UGRP)/glucose-6-phosphatase catalytic subunit-beta results in lowered plasma cholesterol and elevated glucagon. J Biol Chem 2006; 281: 39982-39989.

22. Amulic B, Cazalet $C$, Hayes GL, Metzler KD, Zychlinsky A. Neutrophil function: from mechanisms to disease. Annu Rev Immunol 2012; 30: 459-489.

23. Youle RJ, Strasser A. The BCL-2 protein family: opposing activities that mediate cell death Nat Rev Mol Cell Biol 2008; 9: 47-59.

24. Strasser A. The role of BH3-only proteins in the immune system. Nat Rev Immunol 2005; 5 : 189-200.

25. Puthalakath H, O'Reilly LA, Gunn P, Lee L, Kelly PN, Huntington ND et al. ER stress triggers apoptosis by activating BH3-only protein Bim. Cell 2007; 129: 1337-1349.

26. Hayee B, Antonopoulos A, Murphy EJ, Rahman FZ, Sewell G, Smith BN et al. G6PC3 mutations are associated with a major defect of glycosylation: a novel mechanism for neutrophil dysfunction. Glycobiology 2011; 21: 914-924.

27. Schroder M, Kaufman RJ. The mammalian unfolded protein response. Annu Rev Biochem 2005; 74: 739-789.

28. O'Reilly LA, Huang DC, Strasser A. The cell death inhibitor Bcl-2 and its homologues influence control of cell cycle entry. EMBO J 1996; 15: 6979-6990.

29. Jun HS, Cheung YY, Lee YM, Mansfield BC, Chou JY. Glucose-6-phosphatase-beta, implicated in a congenital neutropenia syndrome, is essential for macrophage energy homeostasis and functionality. Blood 2012; 119: 4047-4055.

30. Pouyssegur J, Shiu RP, Pastan I. Induction of two transformation-sensitive membrane polypeptides in normal fibroblasts by a block in glycoprotein synthesis or glucose deprivation. Cell 1977; 11: 941-947.

31. Metcalf D. Hematopoietic cytokines. Blood 2008; 111: 485-491.

32. Ploner C, Rainer J, Niederegger H, Eduardoff M, Villunger A, Geley S et al. The BCL2 rheostat in glucocorticoid-induced apoptosis of acute lymphoblastic leukemia. Leukemia 2008; 22: 370-377.

33. Yamamoto N, Ueda M, Sato T, Kawasaki K, Sawada K, Kawabata K et al. Measurement of Glucose Uptake in Cultured Cells. Current protocols in pharmacology 2011; Chapter 12 : Unit 12.14.1-22. 